\title{
Needle Tract Lesion
}

National Cancer Institute

\section{Source}

National Cancer Institute. Needle Tract Lesion. NCI Thesaurus. Code C126089.

A localized pathological or traumatic structural change due to insertion and/or withdrawal of a needle. 